\title{
Implementación de una red nacional para la vigilancia de resistencia de agentes patógenos a antimicrobianos según síndromes clínicos
}

\author{
Starting a national surveillance network on antibiotic resistance \\ classified by clinical syndromes
}

La Sociedad Chilena de Infectología es una Sociedad Científica, que desde su fundación, en 1983, se ha preocupado de aunar a infectólogos de adultos, de niños y microbiólogos, de todo el país, en torno a tópicos de vigilancia, prevención, diagnóstico y tratamiento de las enfermedades infecciosas. En este contexto, la preocupación por la resistencia bacteriana y el uso prudente de antimicrobianos ha sido un tema prioritario para nuestra Sociedad. Muchos de nuestros miembros trabajaron arduamente en la década pasada hasta conseguir, en el año 1999, tras un esfuerzo conjunto con el Ministerio de Salud de Chile y otras organizaciones, que se promulgara la ley de regulación de venta de antimicrobianos en Chile, paso fundamental en un largo camino por recorrer aún, para mantener el "uso prudente" de estos medicamentos en nuestro país, que no sólo pasa por regular su venta, sino también otros aspectos, como su licencia, dispensación e indicación por parte nuestra, los médicos.

Un aspecto estrechamente relacionado al uso prudente o imprudente de antimicrobianos en un país es la aparición e incremento de la resistencia bacteriana. ¿qué hemos hecho y qué podemos hacer como organización, para lograr algún control en la resistencia a antimicrobianos?

Nuestro rol como Sociedad Científica es ser un referente técnico, y asesorar a las autoridades en las materias que nos competen, manteniendo una acción eminentemente educativa. Hemos trabajado en definir cómo deben ser usados los antimicrobianos en el ámbito hospitalario y ambulatorio, hemos estado presentes a diario en nuestros lugares de trabajo, tratando de transmitir los conceptos sobre uso racional de antimicrobianos, hemos realizado consensos sobre su indicación en patologías específicas, hemos dado recomendaciones para su uso prudente y hemos difundido nuestros consensos y recomendaciones a través de educación en hospitales de distintas regiones de Chile, de cursos y congresos, y en forma escrita, a través de nuestros órganos de difusión, la Revista Chilena de Infectología y la página WEB de nuestra Sociedad. Al mismo tiempo hemos reflexionado que como país, tenemos la obligación de evaluar nuestros reales niveles de resistencia mediante una red de vigilancia nacional. Esta idea no ha sido nuestra y reconocemos los esfuerzos anteriores realizados en el tema por el Instituto de Salud Publica de Chile (ISP), el Programa de Microbiología del Instituto de Ciencias Biomédicas (ICBM) de la Facultad de Medicina de la Universidad de Chile y el Ministerio de Salud de Chile (MINSAL). El Laboratorio de Referencia del ISP ha recibido por largos años cepas enviadas desde los diferentes Servicios de Salud del país para confirmación y estudios de susceptibilidad; el Programa de Microbiología del ICBM, a cargo de Valeria Prado J, desarrolló el proyecto PRONARES (Programa Nacional de Resistencia), que funcionó entre los años 1998 y 2002, recibiendo cepas referidas por síndromes clínicos, desde un número acotado de hospitales y generó información de gran utilidad para los médicos clínicos; y por último, el MINSAL cuenta con una vigilancia de resistencia de agentes involucrados en infecciones nosocomiales, a través de notificación, la que se utiliza como marcador de infección intrahospitalaria. Nuestro aporte ha sido aunar los esfuerzos de todas las partes involucradas para obtener una información nacional, referida a síndromes clínicos, clasificada por edad y por procedencia (hospitalaria o de la comunidad), de manera de obtener datos de real utilidad para el buen manejo de los pacientes.

Presentamos esta red nacional como un esfuerzo conjunto del ISP y la Sociedad Chilena de Infectología, con el generoso aporte de la experiencia reunida por PRONARES, y como su nombre lo 
indica, la "Red nacional para la vigilancia de resistencia de agentes patógenos a antimicrobianos según síndromes clínicos", tendrá información representativa de todo el país, gracias a un trabajo realmente complementario entre los médicos clínicos y el laboratorio de Microbiología. Cuando dispongamos de una base de datos, capaz de generar verdaderos mapas multicéntricos de resistencia, podremos advertir las tendencias, anticipar los cambios y hacer las llamadas de atención necesarias, manteniendo siempre presente que los profesionales de la salud no debemos perder de vista que el bienestar de los pacientes es el objetivo principal que nos motiva a actuar en salud desde el campo clínico, la epidemiología o el laboratorio, y en ese sentido, el trabajo complementario en busca de información de calidad es lo único que aparece como adecuado y ético.

\section{María Elena Santolaya De P. Presidenta Sociedad Chilena Infectología}

